(1)

CrossMark

\title{
Effect of isoniazid on antigen-specific interferon- $\gamma$ secretion in latent tuberculosis
}

\author{
Martha Torres ${ }^{1}$, Lourdes García-García², Pablo Cruz-Hervert ${ }^{2}$, Heinner Guio ${ }^{3}$, \\ Claudia Carranza', Leticia Ferreyra-Reyes ${ }^{1}$, Sergio Canizales ${ }^{2}$, Susana Molina², \\ Elizabeth Ferreira-Guerrero ${ }^{2}$, Norma Téllez ${ }^{2}$, Rogelio Montero-Campos ${ }^{2}$, \\ Guadalupe Delgado-Sánchez ${ }^{2}$, Norma Mongua-Rodriguez ${ }^{2}$, \\ Jose Sifuentes-Osornio ${ }^{4}$, Alfredo Ponce-de Leon ${ }^{4}$, Eduardo Sada ${ }^{1}$, Douglas \\ B. Young ${ }^{3,5}$ and Robert J. Wilkinson ${ }^{3,5,6}$
}

\begin{abstract}
Affiliations: ${ }^{1}$ Instituto Nacional de Enfermedades Respiratorias, Mexico City, Mexico. ${ }^{2}$ Instituto Nacional de Salud Pública, Cuernavaca, Mexico. ${ }^{3}$ Dept of Medicine, Imperial College, London, UK. ${ }^{4}$ Instituto Nacional de Ciencias Médicas y Nutrición “Salvador Zubirán”, Mexico City, Mexico. ${ }^{5}$ MRC National Institute for Medical Research, London, UK. ${ }^{6}$ Clinical Infectious Diseases Research Initiative, Institute of Infectious Diseases and Molecular Medicine, Faculty of Health Sciences, University of Cape Town, Cape Town, South Africa.
\end{abstract}

Correspondence: Lourdes García-García, Instituto Nacional de Salud Pública, Av. Universidad \# 655, Col. Sta. María Ahuacatitlán, C.P. 62100, Cuernavaca, Morelos, Mexico. E-mail: garcigarmldgmail.com

ABSTRACT Treatment of persons with latent tuberculosis (TB) infection at greatest risk of reactivation is an important component of $\mathrm{TB}$ control and elimination strategies. Biomarkers evaluating the effectiveness of treatment of latent TB infection have not yet been identified. This information would enhance control efforts and assist the evaluation of new treatment regimes.

We designed a two-group, two-arm, randomised clinical study of tuberculin skin test-positive participants: 26 with documented contact with $\mathrm{TB}$ patients and 34 with non-documented contact. Participants in each group were randomly assigned to the immediate- or deferred-isoniazid treatment arms. Assays of in vitro interferon (IFN)- $\gamma$ secretion in response to recombinant Rv1737 and overlapping synthetic peptide pools from various groups of immunodominant proteins were performed.

During isoniazid therapy, a significant increase from baseline in the proportion of IFN- $\gamma$ responders to the 10-kDa culture filtrate protein, Rv2031, Rv0849, Rv1986, Rv2659c, Rv2693c and the recombinant Rv1737 protein was observed ( $\mathrm{p} \leqslant 0.05$ ). The peptide pool of Rv0849 and Rv1737 recombinant proteins induced the highest percentage of IFN- $\gamma$ responders after isoniazid therapy.

The in vitro IFN- $\gamma$ responses to these proteins might represent useful markers to evaluate changes associated with treatment of latent TB infection.

$@$ ERSpublications

Peptide pool of Rv0849 and recombinant protein Rv1737 may be useful to test the efficacy of treatment of latent TB http://ow.ly/Catld

This article has supplementary material available from erj.ersjournals.com

Received: July 042014 | Accepted after revision: Sept 162014 | First published online: Oct 302014

Clinical trial: This study was registered at www.ClinicalTrials.gov with identifier number NCT00293228

Copyright CERS 2015 ERJ Open articles are open access and distributed under the terms of the Creative Commons Attribution Non-Commercial Licence 4.0. 


\section{Introduction}

Persons with latent tuberculosis infection (LTBI) are a large reservoir for potential tuberculosis (TB) reactivation and, thereby, continued transmission [1]. Consequently, targeted treatment of LTBI is an important feature of most TB control programmes [2,3]. Diagnosis of LTBI is based on delayed-type hypersensitivity to an intradermal tuberculin test (TST) or by antigen-specific interferon (IFN)- $\gamma$ release using IFN- $\gamma$ release assays (IGRAs) [4].

Studies of IGRAs (dependent on short-term release of IFN- $\gamma$ in response to the $6-\mathrm{kDa}$ early secretory antigenic target (ESAT-6) and the $10-\mathrm{kDa}$ culture filtrate protein (CFP-10), encoded within region of difference (RD)1, which is absent from Mycobacterium bovis bacille Calmette-Guérin (BCG) and most nontuberculous mycobacteria) have been used to evaluate the efficacy of LTBI treatment [5-7]. Results have been inconsistent using peptides covering whole CFP-10 and ESAT-6; however, interesting results were found using peptides covering only portions of these proteins, both in LTBI and TB therapy follow-up in both low and high TB endemic countries [8-14]. ESAT-6 and CFP-10 are secreted by Mycobacterium tuberculosis under a wide range of growth conditions that include the exponential phase. An alternative hypothesis has been to study proteins that might specifically be up-regulated by bacilli in the latent phase of infection. Hypoxia characterises latent TB granulomas and so attention has been paid to the transcriptional changes that occur in bacilli subject to hypoxia in vitro. Two groups of potential antigens have thereby been identified. 57 genes initially and transiently induced by hypoxia are controlled by a three-component hypoxia-inducible regulon (DosR). The immunodominance of some DosR-regulated proteins has been demonstrated $[15,16]$. Specifically, Rv2628c has been associated with remote LTBI, and has been found in the lungs of both LTBI and active TB patients $[17,18]$.

Prolonged hypoxia (between 24 and $168 \mathrm{~h}$ ) induces a group of $>200$ genes known as the enduring hypoxic response (EHR) [15].

We designed the present study to assess peripheral blood mononuclear cell (PBMC) IFN- $\gamma$ secretion in TST-positive persons in response to a mixture of overlapping peptides from $M$. tuberculosis proteins encoded by DosR regulon or EHR genes, as well as the reference antigens ESAT- 6 and CFP-10, and other members of the es $x$ family, before, during and after isoniazid therapy.

\section{Material and methods}

The study was conducted in Orizaba, Veracruz (Southern Mexico), between September 2008 and September 2009. We designed a two-group, two-arm, randomised clinical study in which healthy, male and female, 15-55-year-old, TST-positive $(>10 \mathrm{~mm}$ by the Mantoux method using 2 tuberculin units of purified protein derivative (PPD) RT-23; Statens Serum Institut, Copenhagen, Denmark) participants were divided in two groups according to their history of previous exposure to a patient with bacteriologically confirmed pulmonary TB (shared household with a patient (so-called documented contacts; groups A and B) or without such a history (so-called non-documented contacts; groups C and D)). Participants in each group were randomly assigned to one of two treatment arms, with isoniazid $\left(5 \mathrm{mg} \cdot \mathrm{kg}^{-1}\right.$ body weight, up to $300 \mathrm{mg}$ per day, for 6 months) as the treatment for LTBI (treatment initiated immediately after recruitment (groups A and C) or treatment deferred for 3 months after recruitment (groups B and D)). Adherence was periodically monitored by measurement of isoniazid metabolites in urine using Taxo-INH strips (Becton Dickinson, Sparks, MD, USA) and pill counting. Participants underwent clinical evaluation at enrolment and at each visit. Groups B and D received fortnightly clinical exams during the deferred phase. Venous blood $(30 \mathrm{~mL})$ was drawn from all subjects for immunological assays at $0,1,4,13,26$ and 40 weeks in groups A and C, and at $0,13,14,17,26,40$ and 54 weeks in groups B and D. All the assays were performed by personnel blinded to participant status. Ethical approval for the protocol was obtained from the ethics review committee of the Instituto Nacional de Salud Pública, Cuernavaca, Mexico, and written informed consent was obtained from all parents, guardians or participants. The study was registered at www.ClinicalTrials.gov with identifier number NCT00293228.

Support statement: This work was funded by the Bill and Melinda Gates Foundation (grants GCGH\#11 reference 37222 and GCGH \#6-74), the US National Institutes of Health (A135969 and K01TW000001), the Wellcome Trust (176W009, 084323 and 088316), the Howard Hughes Medical Institute (55000632) and CONACYT (SALUD 2003-C01-132, SEP-2004-C01-47499/A1, FOSSIS 2005-03 (15203), FOSSIS 2005-2 (14475), SALUD-2008-C01-87332 and SALUD-2010-01-140178). R.J. Wilkinson also received support from the UK Medical Research Council (U1175.02.002.00014.01) and the European Union.

Conflict of interest: Disclosures can be found alongside the online version of this article at erj.ersjournals.com 


\section{Antigens}

We used custom-designed overlapping synthetic peptides covering the proteins sequences of ESAT-6 and CFP-10 (mixtures of 10 peptides of 15-mers overlapping by five residues and divided in two peptide pools). Peptides covering sequences of Rv0081, Rv0569, Rv2031, Rv0288c, Rv3019c, Rv0826, Rv0849, Rv1986, Rv2659c and Rv2693c were mixtures of 10 synthetic 20-mers overlapping by 10 residues (Peptide Synthetics UK and ProImmune, Oxford, UK). The sequence of Rv1986 was covered by two peptide pools. The covered peptide sequences were selected using the protein sequence of each of the genes reported in Tuberculist (http://tuberculist.epfl.ch) and the regions of high similarity in biological sequences with the sequences in the nucleotide database were selected using the National Center for Biotechnology Information Basic Local Alignment Search Tool (www.ncbi.nlm.nih.gov/BLAST/Blast.cgi), as reported in [19]. Sequences are reported in table 1. We also tested recombinant Rv1737 protein kindly donated by

TABLE 1 Peptide sequences

\begin{tabular}{|c|c|c|c|c|}
\hline \multirow[t]{2}{*}{ Peptide } & \multirow[t]{2}{*}{ Gene } & \multirow[t]{2}{*}{ Overlapping sequence } & \multicolumn{2}{|c|}{$\begin{array}{c}\text { Overlapping } \\
\text { synthetic peptides }\end{array}$} \\
\hline & & & $\begin{array}{l}\text { Length } \\
\text { aa }\end{array}$ & $\begin{array}{l}\text { Overlap } \\
\text { aa }\end{array}$ \\
\hline ESAT-6-1 & esxA & $\begin{array}{c}\text { MTEQQWNFAG IEAAASAIQG NVTSIHSLLD EGKQSLTKLA } \\
\text { AAWGGSGSEA YQGVQQ }\end{array}$ & 15 & 5 \\
\hline ESAT-6-2 & esxA & $\begin{array}{c}\text { SGSEA YQGVQQ KWDATATELNNALQ NLARTISEAG } \\
\text { QAMASTEGNV TGMFA }\end{array}$ & 15 & 5 \\
\hline CFP-10-1 & $\operatorname{esx} B$ & $\begin{array}{c}\text { MAEMKTDAAT LAQEAGNFER ISGDLKTQID QVESTAGSLQ } \\
\text { GQWRGAAGTA AQAAV }\end{array}$ & 15 & 5 \\
\hline CFP-10-2 & $e s x B$ & $\begin{array}{c}\text { AAGTA AQAAV VRFQEAANKQKQELD EISTNIRQAG } \\
\text { VQYSRADEEQ QQALSSQMGF }\end{array}$ & 15 & 5 \\
\hline Rv0081 & Rv0081 & $\begin{array}{l}\text { MESEPLYKLK AEFFKTLAHP ARIRILELLV ERDRSVGELL } \\
\text { SSDVGLESSN LSQQLGVLRR AGVVAARRDG NAMIYSIAAP } \\
\text { DIAELLAVAR KVLARVLSDR VAVLEDLRAG GSAT }\end{array}$ & 20 & 10 \\
\hline Rv0569 & Rv0569 & $\begin{array}{l}\text { MKAKVGDWLV IKGATIDQPD HRGLIIEVRS SDGSPPYVVR } \\
\text { WLETDHVATV IPGPDAVVVT AEEQNAADER AQHRFGAVQS } \\
\text { AILHARGT }\end{array}$ & 20 & 10 \\
\hline Rv2031 & $h s p X$ & $\begin{array}{c}\text { MATTLPVQRH PRSLFPEFSE LFAAFPSFAG LRPTFDTRLM } \\
\text { RLEDEMKEGR YEVRAELPGV DPDKDVDIMV RDGQLTIKAE } \\
\text { RTEQKDFDGR SEFAYGSFVR TVSLPVGADE DDIKATYDKG } \\
\text { ILTVSVAVSE GKPTEKHIQI RSTN }\end{array}$ & 20 & 10 \\
\hline Rv0288c & esxH & $\begin{array}{c}\text { MSQIMYNYPA MLGHAGDMAG YAGTLQSLGA EIAVEQAALQ } \\
\text { SAWQGDTGIT YQAWQAQWNQ AMEDLVRAYH AMSSTHEANT } \\
\text { MAMMARDTAE AAKWGG }\end{array}$ & 20 & 10 \\
\hline Rv3019c & esxR & $\begin{array}{c}\text { MSQIMYNYPA MMAHAGDMAG YAGTLQSLGA DIASEQAVLS } \\
\text { SAWQGDTGIT YQGWQTQWNQ ALEDLVRAYQ SMSGTHESNT } \\
\text { MAMLARDGAE AAKWGG }\end{array}$ & 20 & 10 \\
\hline Rv0826 & Rv0826 & $\begin{array}{l}\text { TELPKPPFAQ RVPDWLWAAP RKLLARFFVW LTVGLYDPPV } \\
\text { RELMGYRWLR RDEWLHRRFG DIVRLVFALVPFRFRKHPRA } \\
\text { RAGWDRATGR IPADAPLVQT PARNLPPPDE RDNPTHYCPK V }\end{array}$ & 20 & 10 \\
\hline Rv0849 & Rv0849 & $\begin{array}{l}\text { LPSVLIAAAA TGFAGALFNPAVRGYLAAEA GERKIEAFAM } \\
\text { FNVFYQSGIL LGPLVGLVLL ALDFRITVLA } \\
\text { AAGVFGLLTVAQLVALPQHR ADSEREKTSI }\end{array}$ & 20 & 10 \\
\hline Rv1986-1 & mce3C & $\begin{array}{c}\text { MNSPLVVGFL ACFTLIAAIG AQNAFVLRQG IQREHVLPVV } \\
\text { ALCTVSDIVL IAAGIAGFGA LIGAHPRALN VVKFGGAAFL } \\
\text { IGYGLLAARR AWRPVALIPS }\end{array}$ & 20 & 10 \\
\hline Rv1986-2 & mce3C & $\begin{array}{c}\text { GATPVRLAEV LVTCAAFTFL NPHVYLDTVV LLGALANEHS } \\
\text { DQRWLFGLGA VTASAVWFAT LGFGAGRLRG } \\
\text { FTNPGSWRILDGLIAVMMV ALGISLTVT }\end{array}$ & 20 & 10 \\
\hline Rv2659c & Rv2659c & $\begin{array}{l}\text { AAVRRWYATT AVGTPTMRAH SYSLLRAIMQ TALADDLIDS } \\
\text { NPCRISGAST ARRVHKIRPATLDELETITK AMPDPYQAFV } \\
\text { LMAAWLAMRY GELTELRRKD IDLHGEVARV RRAVVRVGEG }\end{array}$ & 20 & 10 \\
\hline Rv2693c & Rv2659c & $\begin{array}{l}\text { MNANRTSAQR LLAQAGGVSG LVYSSLPVVT FVVASSAAGL } \\
\text { LPAIGFALSM AGLILLWRLL RRESARPVVA GFCGVAVCAL } \\
\text { IAYLVGQSKG YFLLGIWMSL LWAVVFTLSI LIRRPIVGYL }\end{array}$ & 20 & 10 \\
\hline
\end{tabular}

ESAT-6: 6-kDa early secretory antigenic target; CFP-10: 10-kDa culture filtrate protein. 
Tom H.M. Ottenhoff (Leiden University Medical Centre, Leiden, the Netherlands). We also included phytohaemagglutinin (PHA) to test cell viability and tuberculin (PPD). Peptides were dissolved in dimethyl sulfoxide and stock solutions were prepared in RPMI 1640 culture medium at $1 \mathrm{mg} \cdot \mathrm{mL}^{-1}$. Aliquots were stored frozen at $-80^{\circ} \mathrm{C}$ until use.

IFN- $\gamma$ release assay

At scheduled times for each group as described above, $30 \mathrm{~mL}$ heparinized peripheral blood was obtained from each participant. PBMCs were separated by centrifugation using Lymphoprep (Axis-Shield PoC AS, Oslo, Norway) as previously described [20]. PBMCs were cryopreserved at $-70^{\circ} \mathrm{C}$, and were thawed and re-suspended in RPMI 1640 culture medium containing $2 \mathrm{mM}$ L-glutamine (BioWhittaker, Radnor, PA, USA). Viable cells were counted with an inverted microscope using the trypan blue method and, typically, the viability of cells was $\geqslant 93 \%$. PBMCs were plated at $2 \times 10^{5}$ cells per well on flat-bottomed, 96 -well culture plates, and incubated with each mixture of overlapping peptide pools at $5 \mu \mathrm{g} \cdot \mathrm{mL}^{-1}$, recombinant Rv1737 protein at $5 \mu \mathrm{g} \cdot \mathrm{mL}^{-1}, \mathrm{PPD}$ at $10 \mathrm{mg} \cdot \mathrm{mL}^{-1}$, PHA at $10 \mathrm{mg} \cdot \mathrm{mL}$ and culture medium. After 6 days of cultivation at $37^{\circ} \mathrm{C}$ under $5 \%$ carbon dioxide in air, the cell-free supernatants were collected and the secretion of IFN- $\gamma$ was analysed by ELISA.

\section{IFN- $\gamma$ ELISA}

IFN- $\gamma$ levels were quantified by an in-house sandwich ELISA as previously described [21]. The detection limit of the IFN- $\gamma$ ELISA was $8 \mathrm{pg} \cdot \mathrm{mL}^{-1}$. Antigen-specific IFN- $\gamma$ responses were considered positive when values were $>100 \mathrm{pg} \cdot \mathrm{mL}^{-1}$ after subtraction of values obtained from unstimulated cells.

\section{Statistical analysis}

We only analysed the responses from participants with full datasets. Characteristics of participants were compared according to each study group the Mann-Whitney or Chi-squared tests. We compared the IFN- $\gamma$ response (in picograms per millilitre) and the proportion of responders $\left(>100 \mathrm{pg} \cdot \mathrm{mL}^{-1}\right)$ before isoniazid treatment between documented and non-documented contacts, and between each of the two pre-treatment measurements among individuals whose treatment was deferred, using the Kruskal-Wallis and Chi-squared tests. To examine changes during follow-up, we compared the proportion of responders to each antigen at the first post-treatment values (week 1), during treatment (weeks 4,13 and 26) and the last post-treatment measurement (week 40), with the pre-treatment measurement (week 0) using multivariable, random-effects logistic regression models. We calculated the median response for the interval between weeks 4, 13 and 26 to simplify the analysis. In all multivariable analyses, we controlled for age, sex, documented or non-documented contacts, immediate or deferred treatment, degree of smear positivity of the index case, and response to PHA. All analyses were performed using the STATA 13.0 statistical software package (StataCorp LP, College Station, TX, USA).

\section{Results}

\section{Baseline characteristics of participants}

We analysed information on 60 individuals who provided all blood samples. A flow diagram displaying the numbers of individuals at enrolment, intervention allocation, follow-up and analysis is shown in figure 1. Most of the characteristics of participants were similar between groups (table 2), but a significantly higher proportion of women were allocated to group C. Non-documented contacts were older and with greater TST induration than documented contacts. 56 individuals ingested $80 \%$ or more of the indicated pills, and four individuals ingested between $50 \%$ and $79 \%$. Measurements of isoniazid metabolites in urine were positive in $>90 \%$ of the determinations.

\section{Baseline IFN- $\gamma$ production}

No significant differences in the amount of baseline IFN- $\gamma$ production (fig. 2a and online supplementary table S1) or the proportion of individuals (fig. $2 \mathrm{~b}$ and table S1) responding to peptide pools was observed between documented and non-documented contacts. PBMCs from all contacts secreted detectable IFN- $\gamma$ in response to almost all peptide pools and Rv1737 protein (fig. 2a). The strongest stimuli were peptide pools from Rv0849, Rv1986 and Rv1737 protein (fig. 2b and table S1). Among individuals whose isoniazid treatment was deferred, with the exception of CFP10-2, for which the IFN- $\gamma$ response in samples drawn immediately before treatment were significantly higher, there was no difference in IFN- $\gamma$ secretion (fig. $2 \mathrm{c}$ and table S2) or the proportion of participants (fig. $2 \mathrm{~d}$ and table S2) responding to peptide pools at two different time-points before initiating therapy.

\section{IFN- $\gamma$ response to ESAT-6 and CFP-10}

We assessed the response to two peptide pools of both ESAT-6 and CFP-10, which have been used in IFN- $\gamma$ release assays during treatment of LTBI [8-10]. Compared with the baseline, multivariate analyses 


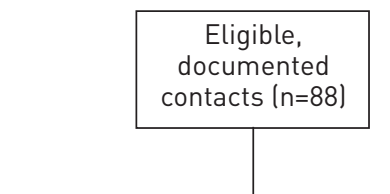

Total excluded $n=27$

Did not meet inclusion criteria $(n=12)$

Refused to participate $(n=12)$ Other reasons $(n=3)$

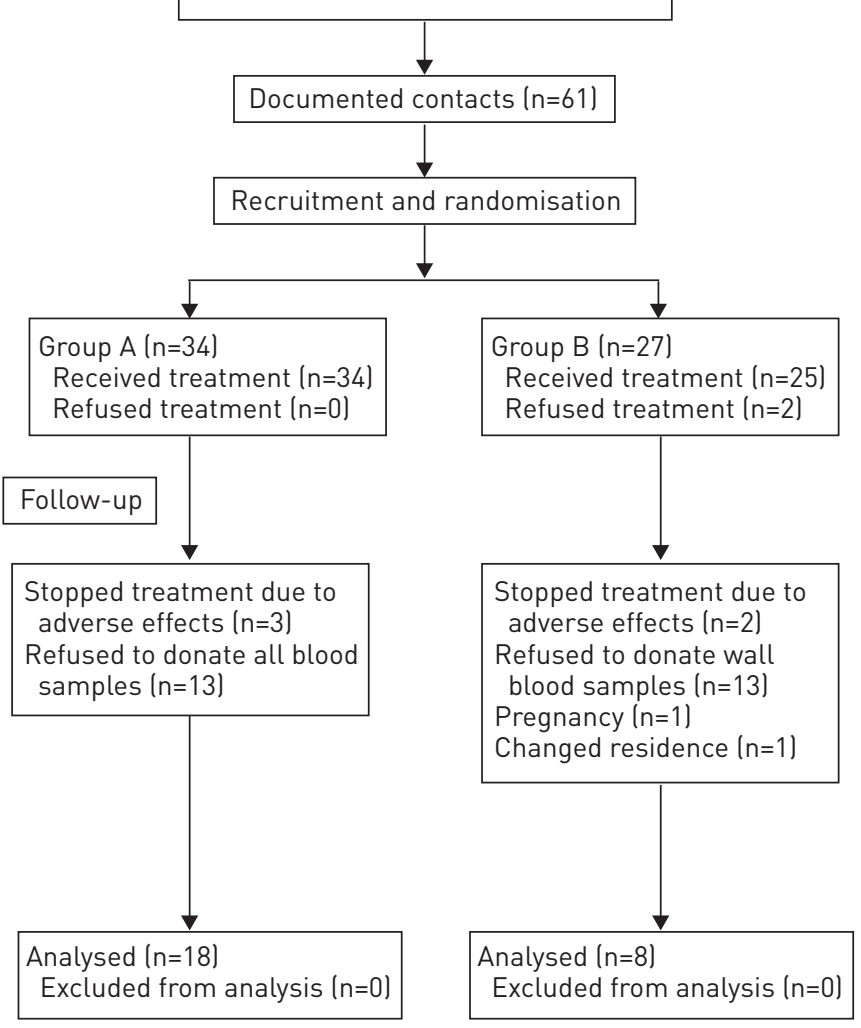

b)

Eligible, non-documented contacts $(n=239)$

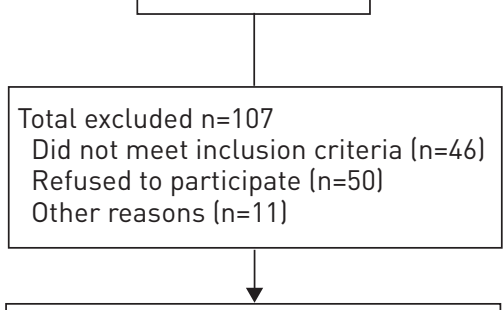

Non-documented contacts ( $n=132)$

Recruitment and randomisation

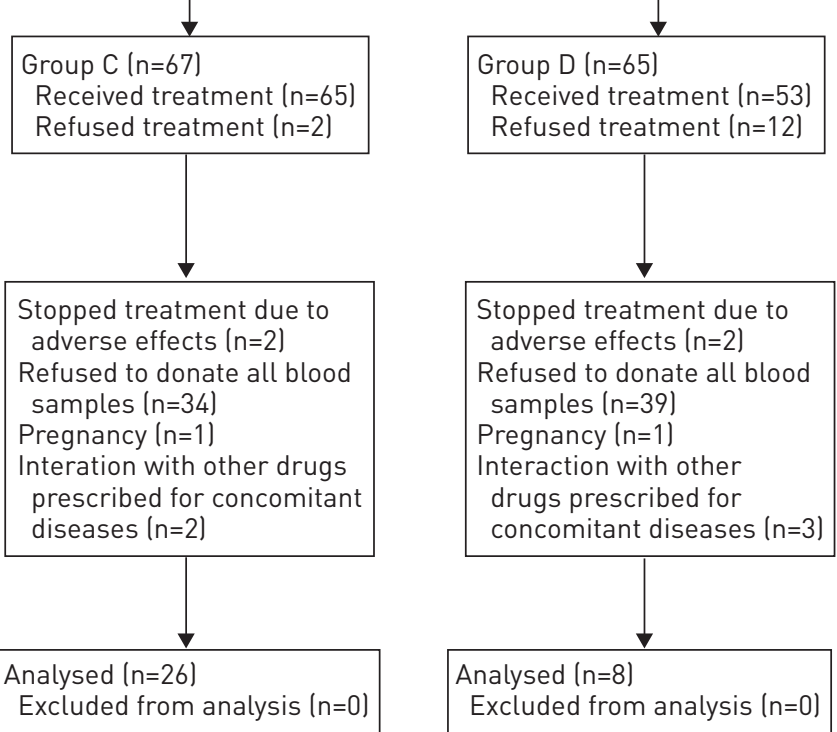

FIGURE 1 Flow diagram of study population. a) Documented contacts. b) Non-documented contacts.

indicated a significant increase in the proportion of responders to CFP-10-1 at week 1 (table 3 and fig. 3a). The increase in response to the rest of the peptides of these proteins and the combined response to ESAT-6 or CFP-10 (table S3 and fig. 3a) were not significant.

\section{IFN- $\gamma$ response to peptides within DosR-regulated proteins}

Multivariate analyses revealed that at week 1 and 40 of isoniazid treatment, there was a significant increase in the proportion of responders to Rv2031 compared with baseline (table 3 and fig. $3 \mathrm{~b}$ ). The IFN- $\gamma$ production in response to Rv0081 and Rv0569 did not significantly change during treatment (table S3 and fig. 3b).

\section{IFN- $\gamma$ response to peptides from esx homologues and EHR antigens}

None of the responses to esx homologue antigens showed significant changes during treatment (table S3 and fig. 3c). As for EHR proteins, after 1 week of isoniazid therapy, there was a significant increase in the odds of a response to Rv0849, Rv1986-2, Rv2659c and Rv2693c. A significant increase at week 40 was also observed for Rv0849, Rv1986-2 and Rv2693c (table 3 and fig. 3d).

\section{IFN- $\gamma$ response to $R v 1737$ protein}

Rv1737 protein induced the highest production of IFN- $\gamma$ among the assessed peptide pools. The odds of a response increased significantly between weeks 4 and 26, and at week 40 (table 3 and fig. 3e). 


\begin{tabular}{|c|c|c|c|c|c|c|c|c|}
\hline Females & $34 / 60$ (56.67) & $9 / 18(50)$ & 2/8 (13.33) & 0.234 & $20 / 26$ (76.92) & $3 / 8$ (37.50) & 0.037 & 0.028 \\
\hline Age $^{f}$ years & 36 (23.5-48) & $25(16-37)$ & $20.5(16-30.5)$ & 0.358 & $45.5(32-50)$ & $46(29.5-50.5)$ & 0.823 & $<0.001$ \\
\hline Formal schooling & $13 / 60(21.7)$ & $3 / 18(16.7)$ & $2 / 8(25)$ & 0.619 & $7 / 26(26.9)$ & $1 / 8(12.5)$ & 0.4 & 0.768 \\
\hline $\begin{array}{l}\text { Household with } \\
\text { earthen floor }\end{array}$ & $20 / 60$ (33.3) & $4 / 18(22.2)$ & $2 / 8(25)$ & 0.877 & $9 / 26(34.6)$ & $5 / 8$ (62.5) & 0.161 & 0.228 \\
\hline Alcohol usage & $25 / 60$ (41.7) & $7 / 18$ (38.9) & $2 / 8(25)$ & 0.492 & $11 / 26$ (42.3) & $5 / 8(62.5)$ & 0.317 & 0.493 \\
\hline Tobacco usage & $17 / 60(28.3)$ & 6/18 (33.3) & $3 / 8(37.5)$ & 0.837 & $4 / 26(15.4)$ & $4 / 8(50)$ & 0.044 & 0.208 \\
\hline
\end{tabular}

Data are presented as $\mathrm{n} / \mathrm{N}(\%)$ or median (interquartile range), unless otherwise stated. $\mathrm{p}$-values were calculated using the Chi-squared test

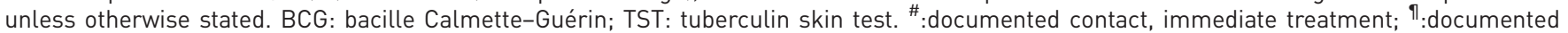
contact, deferred treatment; ${ }^{+}$:non-documented contact, immediate treatment; ${ }^{\S}$ :non-documented contact, deferred treatment; ${ }^{f}:$-values were calculated using the Mann-Whitney test.

\section{Discussion}

There are no reliable biomarkers to evaluate treatment efficacy in LTBI. Previous studies have shown inconsistent or contradictory results, variability depending on study population, prevalence of TB, criteria used to determine LTBI, antibiotics, treatment adherence, type of assay, incubation periods and antigens [6, 8-12, 22-25]. Most of these studies have used assays including ESAT-6 and CFP-10 as mycobacterial antigens; therefore, it has been suggested that a mixture of antigens, including those predominantly secreted in latency, might be a better predictor of M. tuberculosis burden in response to treatment [6]. We therefore analysed IFN $-\gamma$ secretion in response to peptide pools from DosR-regulated, es $x$ homologue, EHR and immunodominant mycobacterial proteins before, during and after treatment with isoniazid. The production of IFN- $\gamma$ in response to peptide pools of CFP-10-1, Rv2031, Rv0849, Rv1986, Rv2659c, Rv2693c and the recombinant Rv1737 protein significantly increased after 1 and/or 40 weeks of isoniazid therapy. The peptide pool of Rv0849 and the Rv1737 recombinant protein induced the highest percentage of responders. These proteins may therefore be useful to evaluate the efficacy of drugs for the treatment of LTBI. Additionally, our results demonstrate that Rv1737 was the most potent inducer of the IFN- $\gamma$ response before isoniazid treatment.

In the absence of isoniazid therapy, although peptide pools from CFP-10 and ESAT- 6 induced a strong IFN $-\gamma$ response, it was lower than that been previously reported [26]. As previously described, ESAT-6 induced lower IFN- $\gamma$ responses than CFP-10 [8]. These variations in immunodominance may result from a variety of factors, as described earlier.

We also identified Rv0849, Rv1737 and the RD2-encoded Rv1986 (absent from most commonly used BCG strains) as major inducers of IFN- $\gamma$ production in individuals with LTBI before isoniazid therapy. Peptides from Rv1986 have previously been reported to induce a strong response in peripheral cells from persons with LTBI and active TB, with a pattern of high interleukin-2 levels compared with IFN- $\gamma$ levels, whereas CFP-10 induces mainly IFN- $\gamma$ [27].

The conserved membrane transport protein Rv0849 has not previously been assessed in LTBI. Conversely, the nitrate/nitrite transporter Rv1737 (NarK2) has been tested previously for IFN- $\gamma$ induction and has been found to be among the most frequently recognised DosR regulon-encoded antigens in Uganda [28]. In our study, Rv1737 was the highest IFN- $\gamma$ inducer. The Rv1737 protein is expressed under hypoxic conditions, being necessary for nitrate respiration during anaerobic conditions, and has been found to be defective in BCG strains [29]. Therefore, the response to this protein most probably results from LTBI, suggesting it could have potential usefulness as a marker of LTBI.

Our results demonstrate that after 1 week of isoniazid therapy, the frequency of IFN- $\gamma$ responders to ESAT- 6 and CFP-10 transiently increased (significantly only for CFP-10-1) but then decreased to baseline levels. The general pattern of response was similar to that in a previous study reporting an increase followed by a decrease in the total number of peripheral cells producing IFN- $\gamma$ in response to recombinant ESAT-6, CFP-10, 30-kDa and $\alpha$-crystallin-1 proteins after 26 days of preventive therapy [9]. This pattern may be explained by an effect of isoniazid on early release and subsequent decrease of secreted 

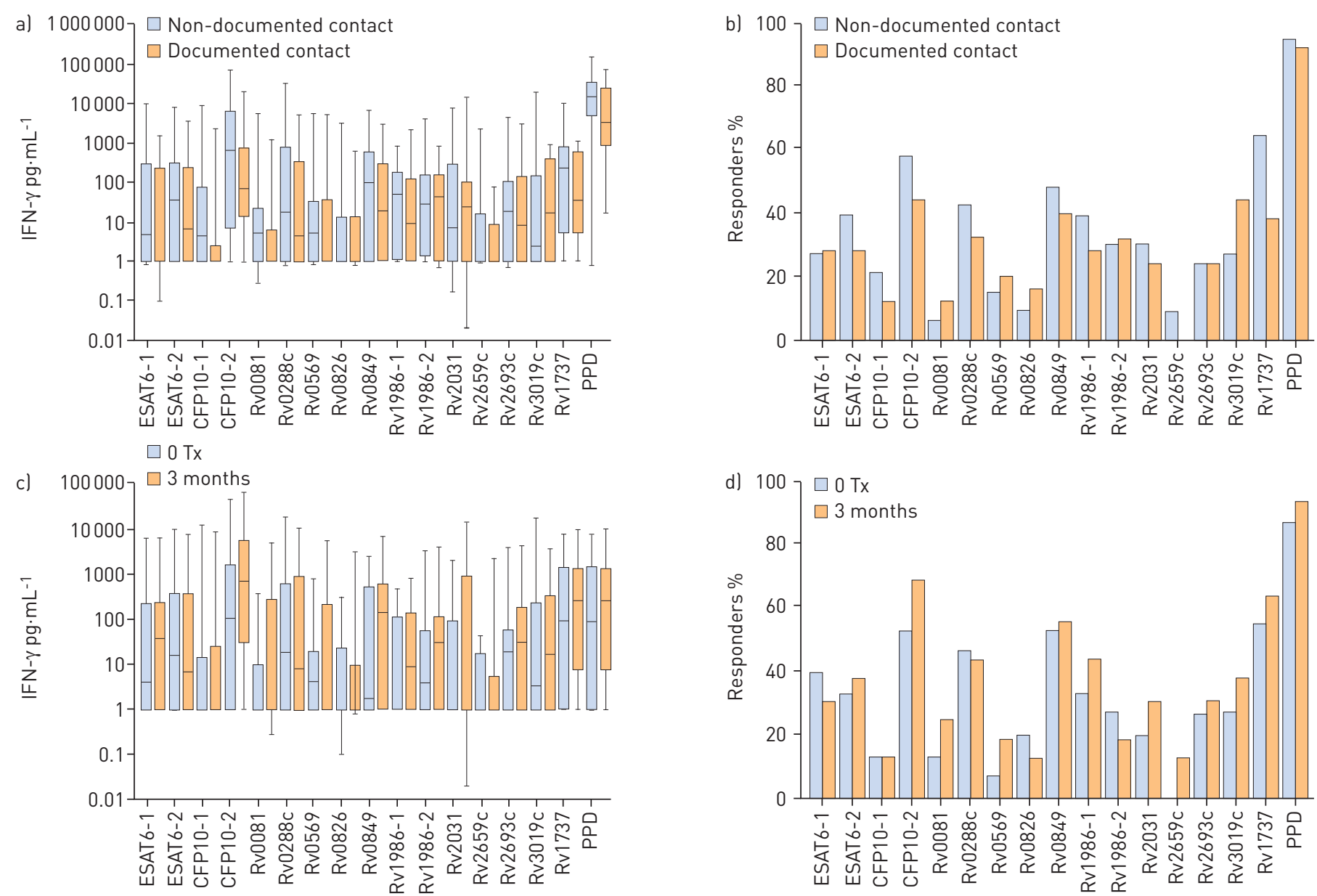

FIGURE 2 a) Interferon (IFN)- $\gamma$ response to the pooled peptides assessed, comparing subjects with and without household contact with a patient with active tuberculosis (TB). b) Percentage of IFN- $\gamma$ responders $\left(>100 \mathrm{pg} \cdot \mathrm{mL}^{-1}\right)$ comparing subjects with and without household contact with a patient with active TB. c) IFN- $\gamma$ response to tested antigens among contacts who were assigned to deferred treatment, comparing the response 3 months before initiating treatment with that on treatment initiation. d) Percentage of IFN- $\gamma$ responders to the assessed antigens among subjects who were assigned to deferred treatment, comparing the response 3 months before initiating treatment with that on treatment initiation. No significant differences in the amount of IFN- $\gamma$ production or the proportion of individuals responding to peptide pools was observed between documented and non-documented contacts. Among individuals whose isoniazid treatment was deferred, with the exception of CFP-10-2, there was no difference in IFN- $\gamma$ secretion or the proportion of participants responding to peptide pools at the two different time-points. Tx: treatment; ESAT-6: 6-kDa early secretory antigenic target; CFP-10: 10-kDa culture filtrate protein; PPD: purified protein derivative.

mycobacterial antigens that are recognised by immune cells. In our study, only levels of IFN- $\gamma$ for CFP-10-1 were different from baseline after 1 week of therapy, and we did not observe significant changes at other time-points during isoniazid treatment. We therefore consider that in this study population, the response to the whole peptide pools of ESAT-6 and CFP-10 may not be a useful tool to track isoniazid therapy.

Peptide pools from the proteins Rv2031, Rv0849, Rv1986-2, Rv2659c and Rv2693c induced a baseline response of up to $45 \%$. Of these proteins, only Rv2031 and Rv1986 had been assessed before [28]. IFN- $\gamma$ production after 1 week of therapy was significantly increased in all of the aforementioned peptide pools. IFN $-\gamma$ response to Rv2659c decreased to baseline levels at week 40, suggesting that response is similar to ESAT-6 and CFP-10. For peptide pools from the proteins Rv2031, Rv0849, Rv1986-2 and Rv2693c, the IFN $-\gamma$ response increased above baseline at completion of treatment. We hypothesise that effective isoniazid therapy caused release of these proteins in contrast to what occurs for ESAT-6 and CFP-10.

In contrast to what has been previously observed for Rv0081 and Rv0569 [28], peptides from proteins Rv0081, Rv0569, Rv0288c, Rv3019c and Rv0826 induced a baseline response $<40 \%$. IFN- $\gamma$ production in response to neither of these peptide pools significantly changed after isoniazid therapy.

The recombinant protein Rv1737 induced significantly increased IFN- $\gamma$ levels throughout treatment. Differences from CFP10-1 and ESAT- 6 may be due to the fact that these proteins are secreted, while 
TABLE 3 Proportion of responders to each peptide pool and Rv1737 protein, and multivariate analysis of changes throughout treatment among antigens showing significant variation compared with baseline

\begin{tabular}{|c|c|c|c|c|c|c|c|c|}
\hline \multirow[t]{2}{*}{ Antigen } & \multicolumn{6}{|c|}{ Responders" \% } & \multicolumn{2}{|c|}{ Multivariate analysis } \\
\hline & 0 weeks & 1 week & 4 weeks & 13 weeks & 26 weeks & 40 weeks & aOR $(95 \% \mathrm{Cl})$ & p-value \\
\hline CFP-10-1 (RD1) & 17 & 34 & 22 & 22 & 18 & 21 & & \\
\hline Baseline & & & & & & & Ref. & \\
\hline 1 week & & & & & & & $3.82(1.45-10.03)$ & 0.006 \\
\hline 4-26 weeks & & & & & & & $1.30(0.58-2.91)$ & 0.514 \\
\hline 40 weeks & & & & & & & $1.38(0.48-3.98)$ & 0.547 \\
\hline Rv2031 (DosR) & 28 & 49 & 31 & 32 & 27 & 48 & & \\
\hline Baseline & & & & & & & Ref. & \\
\hline 1 week & & & & & & & $4.04(1.62-10.07)$ & 0.003 \\
\hline 4-26 weeks & & & & & & & $1.07(0.52-2.22)$ & 0.836 \\
\hline 40 weeks & & & & & & & $3.82(1.46-9.98)$ & 0.006 \\
\hline Rv0849 (EHR) & 45 & 58 & 48 & 52 & 67 & 69 & & \\
\hline Baseline & & & & & & & Ref. & \\
\hline 1 week & & & & & & & $2.23(1.01-4.94)$ & 0.046 \\
\hline 4-26 weeks & & & & & & & $1.74(0.93-3.26)$ & 0.081 \\
\hline 40 weeks & & & & & & & $3.04(1.28-7.22)$ & 0.012 \\
\hline Rv1986-2 (EHR) & 31 & 49 & 32 & 33 & 43 & 50 & & \\
\hline Baseline & & & & & & & Ref. & \\
\hline 1 week & & & & & & & $3.26(1.42-7.46)$ & 0.005 \\
\hline 4-26 weeks & & & & & & & $1.41(0.72-2.75)$ & 0.303 \\
\hline 40 weeks & & & & & & & $2.64(1.11-6.28)$ & 0.028 \\
\hline Rv1986-1 or & 45 & 58 & 39 & 40 & 52 & 54 & & \\
\hline \multicolumn{9}{|l|}{ Rv1986-2 (EHR) } \\
\hline Baseline & & & & & & & Ref. & \\
\hline 1 week & & & & & & & $2.31(1.06-5.03)$ & 0.034 \\
\hline 4-26 weeks & & & & & & & $1.01(0.55-1.87)$ & 0.958 \\
\hline 40 weeks & & & & & & & $1.45(0.64-3.77)$ & 0.372 \\
\hline Rv2659c (EHR) & 5 & 20 & 7 & 13 & 15 & 10 & & \\
\hline Baseline & & & & & & & Ref. & \\
\hline 1 week & & & & & & & $6.81(1.88-24.60)$ & 0.003 \\
\hline 4-26 weeks & & & & & & & $2.87(0.89-9.17)$ & 0.075 \\
\hline 40 weeks & & & & & & & $1.87(0.43-8.03)$ & 0.399 \\
\hline Rv2693c (EHR) & 24 & 41 & 31 & 28 & 43 & 48 & & \\
\hline Baseline & & & & & & & Ref. & \\
\hline 1 week & & & & & & & $2.72(1.19-6.19)$ & 0.017 \\
\hline 4-26 weeks & & & & & & & $1.79(0.91-3.49)$ & 0.086 \\
\hline 40 weeks & & & & & & & $3.48(1.47-8.23)$ & 0.004 \\
\hline $\begin{array}{l}\text { Rv1737 } \\
\quad \text { (recombinant) }\end{array}$ & 56 & 66 & 61 & 68 & 78 & 88 & & \\
\hline Baseline & & & & & & & Ref. & \\
\hline 1 week & & & & & & & $2.56(0.91-7.16)$ & 0.073 \\
\hline 4-26 weeks & & & & & & & $2.81(1.23-6.41)$ & 0.014 \\
\hline 40 weeks & & & & & & & $11.85(3.20-43.83)$ & $<0.001$ \\
\hline
\end{tabular}

These multivariable, random-effects logistic regression models were controlled for age, sex, documented or non-documented contacts, immediate or deferred treatment, degree of smear positivity of the index case, and phytohaemagglutinin as a measure of cell viability. aOR: adjusted odds ratio; CFP-10: 10-kDa culture filtrate protein; RD: region of difference; EHR: enduring hypoxic response. ${ }^{\#}$ : >100 pg. $\mathrm{mL}^{-1}$ interferon- $\gamma$.

expression of Rv1737 increases when M. tuberculosis is subject to hypoxia [16]. Treatment of LTBI may also cause these proteins to be expressed, thus stimulating a higher number of circulating IFN- $\gamma$-producing effector cells.

Our study has some limitations. We based our definition of LTBI on TST reactivity, not response to RD1 antigens. Interpretation of the TST is subject to limitations given its imperfect sensitivity and specificity [30]. This notwithstanding, a recent, highly cited meta-analysis concluded that neither IGRAs nor the TST have high accuracy for the prediction of active TB [30]. Another limitation may be that the study did not have a control population of TST-positive individuals who did not receive LTBI therapy. It is, however, the case that participants were divided into those who received immediate or deferred isoniazid therapy and that no random variation in antigen-specific IFN was noted over 3 months in the deferred group. Another 

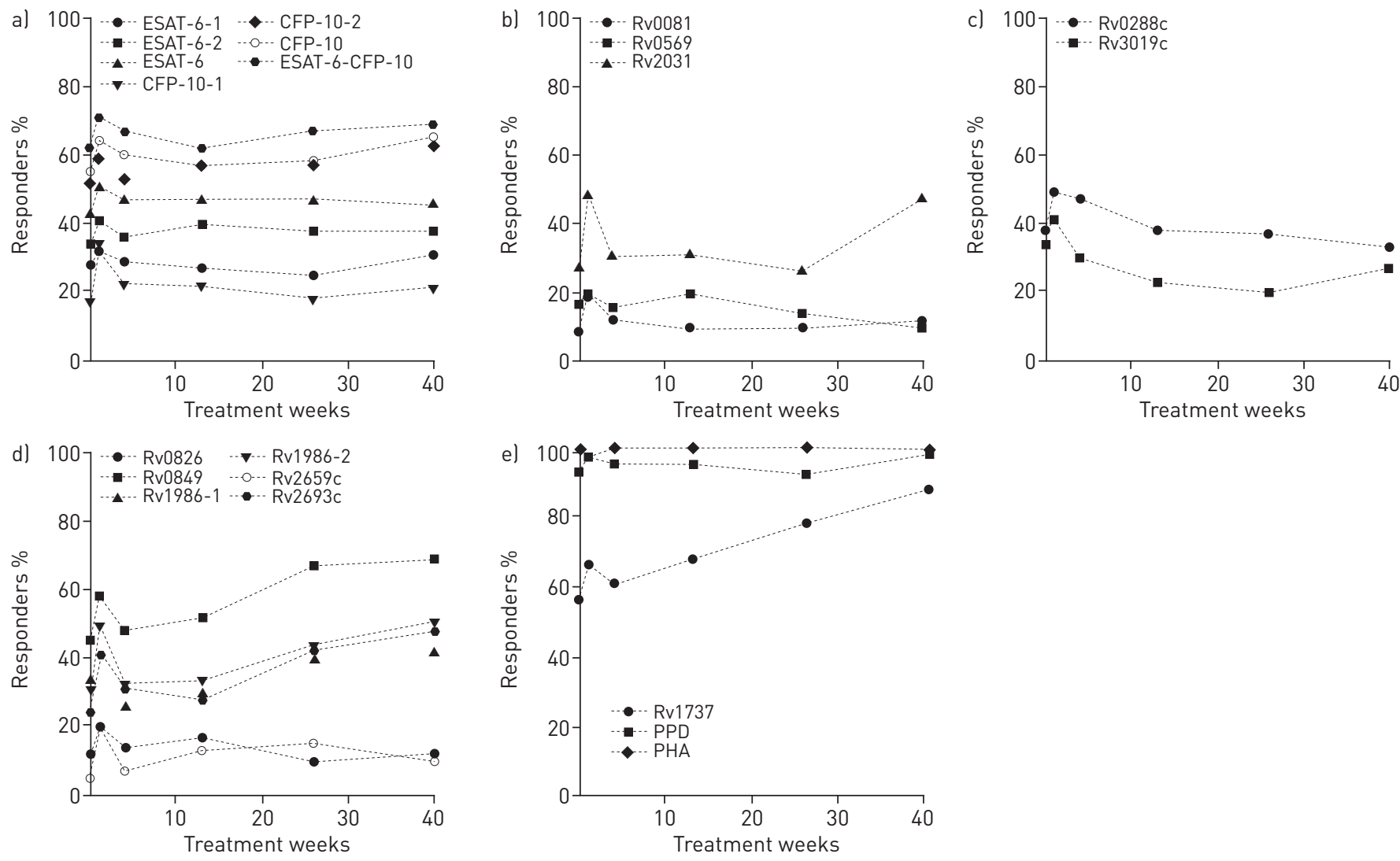

FIGURE 3 Percentage of interferon- $\gamma$ responders during and after isoniazid treatment. a) Percentage of responders to ESAT-6-1, ESAT-6-2, ESAT-6-1 or ESAT-6-2 (labelled as ESAT-6), CFP-10-1, CFP-10-2, CFP10-1 or CFP10-2 (labelled as CFP-10), and combined ESAT-6 or CFP-10 remained similar during and after treatment. b) Responses to Rv0081, Rv0569 and Rv2031 were lower than responses to antigens shown in panel a. The percentage of responders remained stable or slightly increased during or after treatment. c) Responses to Rv0288c and Rv3019c decreased during or after treatment. d) Responses to antigens Rv0826, Rv0849, Rv1986-1, Rv1986-2, Rv2659c and Rv2693c tended to increase during and after treatment. e) Response to Rv1737, purified protein derivative (PPD) and phytohaemagglutinin (PHA). ESAT-6: 6-kDa early secretory antigenic target; CFP-10: 10-kDa culture filtrate protein.

limitation was that the majority of enrolled individuals had a BCG scar and this may have affected the positivity of TST. However, as only a small proportion of subjects who receive the BCG vaccine at birth have a positive TST result 15 years later, it is unlikely that a history of BCG vaccination modified our results, as all our subjects were vaccinated at birth [31]. Another limitation refers to the impact that antecedent TST may have had on our results, as it has been shown that tuberculin may enhance the response to the QuantiFERON Gold In-Tube assay (Qiagen, Venlo, the Netherlands) and, therefore, this important question remains to be fully answered [32]. Finally, we only analysed the responses from participants with full datasets. We encountered difficulty in collecting $30-\mathrm{mL}$ samples of venous blood from patients on seven different occasions. However, full ascertainment of IFN- $\gamma$ secretion in the group who completed all visits allows comprehensive assessment of the IFN- $\gamma$ response to each of the antigens studied.

The strengths of our study include the following: 1) evaluation of a large panel of antigens that included several distinct categories of relevant $M$. tuberculosis antigens; 2) measurements conducted before, during and after treatment, which allowed identification of general patterns of response; and 3) control of relevant confounding variables. Our approach therefore overcomes some of the limitations of previous studies.

In summary, during isoniazid therapy, we observed a significant change of the IFN- $\gamma$ response to CFP-10-1, Rv2031, Rv0849, Rv1986, Rv2659c, Rv2693c and Rv1737 for at least one time-point of the study. The highest frequency of responders was observed after 40 weeks of treatment and occurred in response to Rv0849 and Rv1737 (69\% and 88\%, respectively). This is the first reported study where the production of IFN- $\gamma$ in response to these proteins has been evaluated after isoniazid therapy, suggesting potential usefulness of these proteins as biomarkers when evaluating LTBI treatment. More extensive and controlled longitudinal studies will be needed to confirm these findings. Our results demonstrated significant changes for specific antigens, showing how this approach may assist development of surrogates of LTBI treatment efficacy. 


\section{Acknowledgements}

We thank Kees L.M.C. Franken and Tom H.M. Ottenhoff (Dept of Infectious Diseases, Leiden University Medical Center, Leiden, the Netherlands) for their generous donation of the antigens that were tested. We thank the health authorities from the Orizaba Health Jurisdiction of Mexico for their kind support and cooperation.

\section{References}

1 Dye C, Glaziou P, Floyd K, et al. Prospects for tuberculosis elimination. Ann Rev Pub Health 2013; 34: 271-286.

2 Barry CE 3rd, Boshoff HI, Dartois V, et al. The spectrum of latent tuberculosis: rethinking the biology and intervention strategies. Nat Rev Microbiol 2009; 7: 845-855.

3 Targeted tuberculin testing and treatment of latent tuberculosis infection. American Thoracic Society. MMWR Recomm Rep 2000; 49: 1-51.

4 Munoz L, Santin M. Interferon- $\gamma$ release assays versus tuberculin skin test for targeting people for tuberculosis preventive treatment: an evidence-based review. J Infect 2013; 66: 381-387.

5 Brock I, Munk ME, Kok-Jensen A, et al. Performance of whole blood IFN- $\gamma$ test for tuberculosis diagnosis based on PPD or the specific antigens ESAT-6 and CFP-10. Int J Tuberc Lung Dis 2001; 5: 462-467.

6 Adetifa IM, Ota MO, Jeffries DJ, et al. Interferon- $\gamma$ ELISPOT as a biomarker of treatment efficacy in latent tuberculosis infection: a clinical trial. Am J Respir Crit Care Med 2013; 187: 439-445.

7 Johnson JL, Geldenhuys $\mathrm{H}$, Thiel BA, et al. Effect of isoniazid therapy for latent $\mathrm{TB}$ infection on QuantiFERON-TB gold in-tube responses in adults with positive tuberculin skin test results in a high TB incidence area: a controlled study. Chest 2014; 145: 612-617.

8 Chee $\mathrm{CB}$, KhinMar KW, Gan SH, et al. Latent tuberculosis infection treatment and T-cell responses to Mycobacterium tuberculosis-specific antigens. Am J Respir Crit Care Med 2007; 175: 282-287.

9 Wilkinson KA, Kon OM, Newton SM, et al. Effect of treatment of latent tuberculosis infection on the T cell response to Mycobacterium tuberculosis antigens. J Infect Dis 2006; 193: 354-359.

10 Pai M, Joshi R, Dogra S, et al. Persistently elevated $\mathrm{T}$ cell interferon- $\gamma$ responses after treatment for latent tuberculosis infection among health care workers in India: a preliminary report. J Occup Med Toxicol 2006; 1: 7.

11 Ewer K, Millington KA, Deeks JJ, et al. Dynamic antigen-specific T-cell responses after point-source exposure to Mycobacterium tuberculosis. Am J Respir Crit Care Med 2006; 174: 831-839.

12 Goletti D, Parracino MP, Butera O, et al. Isoniazid prophylaxis differently modulates T-cell responses to RD1-epitopes in contacts recently exposed to Mycobacterium tuberculosis: a pilot study. Respir Res 2007; 8: 5 .

13 Kabeer BS, Raja A, Raman B, et al. IP-10 response to RD1 antigens might be a useful biomarker for monitoring tuberculosis therapy. BMC infectious diseases 2011; 11: 135.

14 Latorre I, Altet N, de Souza-Galvao M, et al. Specific Mycobacterium tuberculosis T cell responses to RD1-selected peptides for the monitoring of anti-tuberculosis therapy. Scand J Infect Dis 2012; 44: 161-167.

15 Rustad TR, Harrell MI, Liao R, et al. The enduring hypoxic response of Mycobacterium tuberculosis. PLoS One 2008; 3: e1502.

16 Sherman DR, Voskuil M, Schnappinger D, et al. Regulation of the Mycobacterium tuberculosis hypoxic response gene encoding $\alpha$-crystallin. Proc Natl Acad Sci USA 2001; 98: 7534-7539.

17 Goletti D, Butera O, Vanini V, et al. Response to Rv2628 latency antigen associates with cured tuberculosis and remote infection. Eur Respir J 2010; 36: 135-142.

18 Chiacchio T, Petruccioli E, Vanini V, et al. Higher frequency of T-cell response to $M$. tuberculosis latency antigen Rv2628 at the site of active tuberculosis disease than in peripheral blood. PLoS One 2011; 6: e27539.

19 Gideon HP, Wilkinson KA, Rustad TR, et al. Bioinformatic and empirical analysis of novel hypoxia-inducible targets of the human antituberculosis T cell response. J Immunol 2012; 189: 5867-5876.

20 Bøyum A. Isolation of lymphocytes, granulocytes and macrophages. Scand J Immunol 1976; 5: Suppl. 9-15.

21 Herrera MT, Torres M, Nevels D, et al. Compartmentalised bronchoalveolar IFN- $\gamma$ and IL-12 response in human pulmonary tuberculosis. Tuberculosis (Edinb) 2009; 89: 38-47.

22 Higuchi $\mathrm{K}$, Harada $\mathrm{N}$, Mori T. Interferon- $\gamma$ responses after isoniazid chemotherapy for latent tuberculosis. Respirology 2008; 13: 468-472.

23 Bastos ML, Menzies D, Belo MT, et al. Changes in QuantiFERON ${ }^{\star}-$ TB Gold In-Tube results during treatment for tuberculous infection. Int J Tuberc Lung Dis 2013; 17: 909-916.

24 Pollock NR, Kashino SS, Napolitano DR, et al. Evaluation of the effect of treatment of latent tuberculosis infection on QuantiFERON-TB gold assay results. Infect Control Hosp Epidemiol 2009; 30: 392-395.

25 Lee SH, Lew WJ, Kim HJ, et al. Serial interferon-gamma release assays after rifampicin prophylaxis in a tuberculosis outbreak. Respir Med 2010; 104: 448-453.

26 Lalvani A, Nagvenkar P, Udwadia Z, et al. Enumeration of T cells specific for RD1-encoded antigens suggests a high prevalence of latent Mycobacterium tuberculosis infection in healthy urban Indians. J Infect Dis 2001; 183: 469-477.

27 Gideon HP, Wilkinson KA, Rustad TR, et al. Hypoxia induces an immunodominant target of tuberculosis specific T cells absent from common BCG vaccines. PLoS pathogens 2010; 6: e1001237.

28 Black GF, Thiel BA, Ota MO, et al. Immunogenicity of novel DosR regulon-encoded candidate antigens of Mycobacterium tuberculosis in three high-burden populations in Africa. Clin Vaccine Immunol 2009; 16: 1203-1212.

29 Honaker RW, Stewart A, Schittone S, et al. Mycobacterium bovis BCG vaccine strains lack narK2 and narX induction and exhibit altered phenotypes during dormancy. Infect Immun 2008; 76: 2587-2593.

30 Rangaka MX, Wilkinson KA, Glynn JR, et al. Predictive value of interferon- $\gamma$ release assays for incident active tuberculosis: a systematic review and meta-analysis. Lancet Infect Dis 2012; 12: 45-55.

31 Menzies R, Vissandjee B. Effect of bacille Calmette-Guérin vaccination on tuberculin reactivity. Am Rev Respir Dis 1992; 145: 621-625.

32 O'Shea MK, Fletcher TE, Beeching NJ, et al. Tuberculin skin testing and treatment modulates interferon-gamma release assay results for latent tuberculosis in migrants. PLoS One 2014; 9: e97366. 